\title{
Real Options and the Costs of the Local Telecommunications Network*
}

\author{
by Nicholas Economides **
}

June 1999

\begin{abstract}
The Telecommunications Act of 1996 invites entry in the local telecommunications networks whereby entrants will lease parts of the network ("unbundled network elements") from incumbents "at cost plus reasonable profit." A crucial question in the implementation of the Act is the appropriate measure of cost. This paper examines the economic principles on which the cost calculation should be based. I conclude that the appropriate measure of cost (maximizing allocative, productive, and dynamic efficiency) is forward-looking economic cost and not the historical, accounting, or embedded cost of the incumbent's network. In calculating costs, demand and supply uncertainty, as well as the asymmetric position of incumbents and entrants should be taken into account. Close examination of the issue of uncertainty in the local telecommunications network reveals that (i) for most unbundled network elements, there is little demand uncertainty; and (ii) that those elements that face significant uncertainty, do not have sunk value. Thus, the incumbent does not face higher expected cost by investing. Moreover, the rewards of the incumbent can be higher because buyers prefer to buy services from the owner of the network. Finally, strategic considerations in oligopolistic interaction are likely to dominate any uncertainty considerations and will increase the incentive of incumbents to invest.
\end{abstract}

Key words: telecommunications, regulation, cost, real options

JEL classification: L1, D4

* Forthcoming in The New Investment Theory of Real Options and its Implications for the Cost Models in Telecommunications, James Alleman and Eli Noam (eds.), Kluwer, 2000. Presented at the conference on "Costs of the Local Telecommunications Network," Columbia University, October 2, 1998.

* Stern School of Business, New York University, 44 West $4^{\text {th }}$ Street, New York, NY 10012, e-mail: neconomi@ stern.nyu.edu, WWW: http://raven.stern.nyu.edu/networks 
On February 1, 1996, President Clinton signed into law the Telecommunications Act of 1996 (1996 Act). This was the first major reform since the original 1934 Telecommunications Act. In passing the 1996 Act, Congress took radical steps toward a major restructuring of the U.S. telecommunications markets. These steps may result in very significant benefits to consumers of telecommunications services, telecommunications carriers, and telecommunications equipment manufacturers. But the degree of success of the 1996 Act depends crucially on its implementation through decisions of the Federal Communications Commission and state public utility commissions, as well as the outcomes of the various court challenges that these decisions, and the Act itself, face.

The Act attempts to introduce and enhance competition in all parts of the telecommunications network. It envisions a network of interconnected networks that are composed of complementary components and generally provide both competing and complementary services. The 1996 Act uses both structural and behavioral instruments to accomplish its goals. It attempts to reduce regulatory barriers to entry and competition. It also outlaws artificial barriers to entry in local exchange markets in its attempt to accomplish the maximum possible competition.

The 1996 Act attempts to enhance competition in telecommunications markets wherever it exists and establish it where it does not. Before competition takes hold, the Act attempts to create conditions that imitate competition in the local exchange. To facilitate entry in the local exchange, the Act mandates the interconnection of telecommunications networks, unbundling, non-discrimination, number portability, and 
cost-based pricing of leased parts of the network, so that competitors can enter easily and compete component by component as well as service by service.

\section{Cost Principles for Leasing of Unbundled Network Elements in}

\section{Implementing the 1996 Act}

Currently, the "last mile" of the telecommunications network that is closest to the consumer (the "local loop") remains a bottleneck controlled by an incumbent local exchange carrier (ILEC), a Regional Bell Operating Company, GTE, or a smaller independent. The 1996 Act boldly attempts to introduce competition in this last bottleneck, and in all parts of the local exchange market, while preserving the effective competition that has developed in the long distance market. Before competition takes hold, the Act attempts to create conditions that imitate competition in the local exchange.

To facilitate entry in the local exchange, the Act imposes mandatory interconnection, unbundling, and number portability. In particular, Section 251(c)(2) mandates:

“interconnection,

(B) at any technically feasible point

(C) that is at least equal in quality to that provided by the local exchange carrier to itself or to any subsidiary, affiliate, or any other party to which the carrier provides interconnection; and

(D) on rates, terms, and conditions that are just, reasonable, and nondiscriminatory, in accordance with the terms and conditions of the agreement and the requirements of this section and section 252." 
Section 251(c)(3) mandates unbundling, that is, offering for sale network elements at "rates, terms, and conditions that are just, reasonable, and nondiscriminatory." The 1996 Act allows for entry in the local exchange through the leasing of unbundled network elements from the ILEC.

Entry through leasing unbundled network elements would be uneconomical unless prices for the leased elements were set appropriately to imitate competitive prices. The 1996 Act orders that the pricing of interconnection or unbundled network elements [252(d)(1)]

“(A) shall be

(i) based on the cost (determined without reference to a rate-of-return or other rate-based proceeding) of providing the interconnection or network element (whichever is applicable), and

(ii) nondiscriminatory, and

(B) may include a reasonable profit."

The measure of cost has been the subject of considerable controversy. The Federal Communications Commission (FCC) and state public utilities commissions (PUCs) have ruled that the word "cost" in Section 252(d)(1) should

(1) be a forward-looking economic cost

(2) be the least cost to provide the service

(3) be a long-run cost

(4) be an incremental cost corresponding to the particular network element

(5) include a competitive return on capital

(6) exclude monopoly rents 
(7) exclude cross-subsidies of any kind

(8) in general, should reflect cost differences among geographic regions.

Moreover, any cost calculation of unbundled network elements (UNEs) should be based on cost-causation: only costs caused by the production of an element should be included in the calculation of its cost.

Total element long-run incremental cost (TELRIC) is the sum of minimized costs paid for all inputs required to supply the unbundled network element. TELRIC conforms to the eight principles above.

Using TELRIC as the basis for prices performs several functions which, in combination, guarantee economic efficiency. First, it gives the right signal to consumers in making purchasing decisions among goods, because then these decisions are made on the basis of what society must give up to supply these goods. In other words, it achieves allocative efficiency. Second, such a price directs production to the most efficient, leastcost suppliers, because these producers can offer the lowest prices. Thus, it achieves productive efficiency. Third, it gives the appropriate signal to firms in decisions on investment, entry, and exit, because firms make these decisions purely on the basis of forward-looking costs. In other words, it achieves dynamic efficiency.

It is incorrect to use embedded, historical, or book costs. True common (firmwide) costs are minimal. A percentage of common costs "attributable" to an element may be added to the TELRIC of an element. Any significant deviation of prices above TELRIC creates efficiency losses. 
The interpretation of the Act by the FCC and the PUCs does not allow unbundled network elements to be leased at a price equal to private opportunity cost, since private opportunity cost

- $\quad$ is based on the final price of the service for which the element is used

- typically includes the supernormal profits of the incumbent

- may include past inefficiencies reflected in higher than efficient costs.

Therefore, the Act does not allow UNEs to be leased at prices based on the "efficient component pricing rule" (ECPR) or its variant (M-ECPR).

\section{On Depreciation, Cost of Capital, and Real Options}

The cost of capital calculation accepted by most regulatory commissions has been challenged by Professor Hausman in two ways. ${ }^{1}$ The first is that variable rates of depreciation are not employed in the typical models and PUC orders that assume straightline depreciation. But, because the calculation of TELRIC or TSLRIC can accommodate variable-rate (not straight-line) depreciation, any criticism of this sort can be easily accommodated. In such a setup, one can have higher depreciation in the early years and lower depreciation in the later years.

Professor Hausman's second challenge to the way depreciation is employed in the typical models and PUC orders is more substantial. He claims that the ILEC, by investing in a network element that an entrant is going to lease, loses the option value of not investing, say, in the case when demand would drop. Professor Hausman concludes that the incorrect capital cost is used in the TELRIC of some network elements.

\footnotetext{
$1 \quad$ See Hausman (1998).
} 
In order for Professor Hausman's proposed argument to have a chance at being correct, it must meet two requirements:

1. The network element for which the real options issue could apply needs to have significantly lower resale value, i.e., its cost needs to be sunk to a significant extent.

2. The ILEC must face significant uncertainty about the network elements of zero resale value.

It is very unlikely that both of these requirements can be fulfilled for any network element of the telecommunications network. To start, many of these network elements, such as electronics, can be moved and/or resold at almost full value, or can be used for other functions. Because such elements do not have zero resale value, they fail the first requirement. Applying real options theory will not increase their cost estimates. Moreover, many network elements fail the second criterion because there is no significant uncertainty about their demand. For example, the ILEC rarely faces much uncertainty about local loops that are arguably the most likely to be purchased by competitive local exchange carriers (CLECs). In the absence of demand uncertainty, the application of real options theory will not increase the cost estimates of such elements.

There is also a fundamental criticism of the basic assumptions under which real options theory has been developed in contrast with the conditions that now prevail and are expected to prevail in the telecommunications industry in the United States. Real options theory assumes that the ILEC will remain a monopolist and has the luxury of putting off investment (because it faces no competitors). Real options theory is based on 
Dixit and Pindyck (1994), who do not consider or prove results for conditions of oligopolistic interaction. $^{2}$

Intuition suggests that, in oligopoly, contrary to the monopoly results of Dixit and Pindyck, firms may invest much more aggressively because of strategic reasons - so that the investing firm is the one to control and lease its network, rather than leasing it from others. Because most of the investments in ILEC equipment for which costs need to be estimated were made in the 1990s, when competition was anticipated, it is absurd to assume that investment occurred with the anticipation that the ILEC would remain a monopolist. In the current oligopolistic environment with anticipation of competition, firms invest looking forward to competition and cannot afford to wait; the value to an ILEC of waiting to invest may well be negative. Finally, it is a well known fact that large customers of telecommunications services are willing to pay more for services provided by an integrated provider than for resold services. For these reasons, contrary to Professor Hausman's claim, the application of real options theory to the conditions of the telecommunications market may well imply a lower cost for the affected unbundled network elements than if real options theory was not applied.

\section{Concluding Remarks}

The Telecommunications Act of 1996 attempts to introduce and enhance competition in all parts of the telecommunications network. To facilitate entry in the local exchange, the Act imposes mandatory interconnection, unbundling, and number portability. The Act mandates that ILECs lease, at cost, parts of their network (unbundled

\footnotetext{
2 Examinations of the same problem by Trigeorgis (1996) and Economides and Trigeorgis (1999) reveal that the logic of Dixit and Pindyck does not necessarily hold in oligopoly.
} 
network elements) to potential entrants. The FCC and state PUCs have ruled that the appropriate cost is forward-looking least economic cost. In calculating the cost of the UNEs, it is important to define correctly the cost of capital.

Based on the theory of real options, Professor Hausman claims that the cost of capital to be used in these calculations should be very significantly higher because, in investing, the incumbent faces risks that the entrant/buyer does not. However, a closer examination of the conditions in the U.S. telecommunications market as well as the assumptions of real options theory reveals that it is very unlikely that a higher cost of capital should apply to any unbundled network elements, and in fact, it could possibly result in a lower cost for the affected unbundled network elements.

First, there are no real options theory results under conditions of oligopoly where the investing firm may have a strategic advantage over a reseller. Second, large customers prefer to buy from an owner rather than a reseller. Thus, the value of a network is higher for the investing firm than a reseller. Third, according to real options theory, the cost of capital for a UNE may be higher only if two requirements are met: the network element has zero resale value, (i.e., its cost is sunk) and there is significant uncertainty about the network elements of zero resale value. These conditions are very difficult for most unbundled network elements to meet. For example, many network elements of the telecommunications network, such as electronics, can be moved and/or resold at almost full value, or can be used for other functions, and therefore their costs are not sunk. Moreover, ILECs face no significant uncertainty in the demand for network elements such as the local loop that are the most likely to be purchased by CLECs, and therefore the issue of real options does not arise for them. Thus, applications of real options theory 
to the conditions of the telecommunications market may well imply a lower cost for the affected unbundled network elements than if real options theory were not applied. 


\section{Bibliography}

Dixit, A.K., and R.S. Pindyck, 1994, Investment under Uncertainty (Princeton University Press, Princeton NJ).

Economides, N., and L. Trigeorgis, 1999, "Real Options in Oligopolistic Interaction," forthcoming.

Hausman, J., 1998, “Testimony before the California Public Service Commission,” April 7.

Trigeorgis, L., 1996, Real Options: Management Flexibility and Strategy in Resource Allocation, MIT Press, Cambridge, Mass. 